Quebec Cooperative Study

of Friedreich's Ataxia

\title{
Oculomotor Abnormalities in Friedreich's Ataxia
}

\author{
T. H.KIRKHAM, D.GUITTON, A. KATSARKAS, L. B. KLINE AND E. ANDERMANN
}

\begin{abstract}
SUMMARY: A clinical neuro-opthalmological and electro-oculographic study was made on fourteen patients with Friedreich's ataxia. None had evidence of optic nerve dysfunction. No patient complained of oscillopsia although all had ocular motor deficits of varying degrees, which appeared to be related to the severity of the general manifestations of the disease. The defects comprised square wave jerks, jerky pursuit with inability to maintain eccentric gaze resulting in gaze paretic nystagmus and rebound nystagmus. There was failure
\end{abstract}

RÉSUMÉ: Une étude des mouvements oculaires, clinique et électro-oculographique a été accomplie chez 14 malades souffrant d'ataxie de Friedreich. Chaque patient a présenté des anomalies de la motricité oculaire; l'importance de ces troubles a semblé être reliée à la sévérité générale de la maladie. Aucun malade ne s'est plaint de troubles visuels. Nous n'avons trouvé aucun trouble de la motricité oculaire ches 17 proches parents de ces malades.

Les caractéristiques suivantes ont été remarquées: (1) ondes carrées; (2) poursuite saccadique; (3) nystagmus relié à la parésie du regard "gaze paretic nystagmus": l'impossibilité de maintenir une déviation eccentrique stable du regard to suppress by fixation the vestibuloocular reflex. The slow phase velocity of caloric ny'stagmus was always of reduced velocity. There was inability to augment the slow phase velocity of optokinetic nystagmus with increasing stimulus velocity. Abnormalities of the saccadic system were manifest particularly as hypermetria. These signs in combination are suggestive of disease involving the cerebellar flocculus and vermis or their brain stem connections. No abnormalities w'ere found in 17 parents or siblings.

donnant suite à un glissement des yeux vers la position primaire, suivi par une saccade vers la périphérie; (4) "rebound nystagmus", le retour à la position primaire a mis en evidence un nystagmus de rebond en sens opposé au nystagmus se manifestant en position eccentrique; (5) l'impossibilité d'utiliser la fixation pour supprimer le réflexe vestibulo-oculaire; (6) lenteur anormale des phases lentes du nystagmus d'origine calorique; (7) aucune augmentation de la vitesse de la phase lente du nystagmus optocinétique en fonction de la vitesse du stimulus; (8) hypermétrie des saccades. Globalement ces signes indiquent une atteinte ou auflocculus et vermis du cervelet ou à leurs connections avec le tronc cérébral.
From the McGill University Departments of Neurology, Neurosurgery, Opthalmology, Otolaryngology, and Neurogenetics, the Montreal Neurological Hospital and Institute and the Royal Victoria Hospital, Montreal, Quebec, Canada.

Reprint requests for the complete supplement on Friedreich's Ataxia (Phase Two, Part Two) to: Dr. André Barbeau, M.D., Clinical Research Institute of Montreal, 110 Pine Avenue West, Montreal, Quebec, Canada H2W IR7.

\section{INTRODUCTION}

Fried reich's ataxia, despite its original detailed description between 1861 and 1877 , has resisted precise clinical or biochemical classification (Andermann, 1976). The object of the present report is to outline the clinical neuroophthalmic and electrooculographic findings in 14 patients with "typical" Friedreich's ataxia as defined in The Quebec Co-operative Study of Friedreich's Ataxia (Geoffroy et al, 1976; Barbeau, 1978). Of the 14 patients, the 8 who were examined by electromyography showed normal motor but absent sensory action potentials in the digital and sural nerves. The disease is inherited as an autosomal recessive trait (Andermann et al, 1976).

\section{MATERIAL AND METHODS}

Clinical neuro-ophthalmic examinations were made on 14 patients. There were 7 males and 7 females and their ages ranged from 15 years to 42 years with a mean of 29 years. Five patients were examined more than once, with an interval of 12 to 26 months between examinations. Electro-oculography was performed on 11 patients to document and supplement the clinical findings. In addition, 17 siblings and parents were examined in order to detect minor abnormalities in heterozygotes or early manifestations of possible Friedreich's ataxia in younger siblings.

Visual acuity for distance, near, and color vision was determined in all patients. Pupillary reactions were assessed. Visual field examination on the Goldmann perimeter was possible in 9 cases. Fundus examination was routinely performed after dilatation of the pupils. Ocular motility was examined clinically with respect to ocular alignment and pursuit capabili- 
ties. The presence of nystagmus was sought in horizontal and vertical planes and rebound nystagmus was carefully looked for on return to the midline after eccentric gaze had been maintained for 20 seconds. Optokinetic responses to a hand-held rotating drum were studied. The ability to suppress the vestibulo-ocular reflex in the horizontal and vertical planes was noted (Zee, 1977). Saccadic accuracy and velocity was studied. Following the clinical examination, electrooculography was performed.

The eye movements were recorded using Beckman miniature silver-silver chloride skin electrodes. The horizontal eye movements were recorded separately for each eye and vertical movements from the right eye were also recorded. Rectilinear recordings were made on a standard chart recorder after $\mathrm{AC}$ amplification with a time constant of 3 seconds and a band width of $30 \mathrm{~Hz}$. Calibration of the recording, which also gave the performance of the eyes during horizontal saccadic movements, was performed by asking the patient to make re-fixation saccades to targets of $10^{\circ}$ to the right and left of the midline. We measured the velocities and accuracy of $10^{\circ}$ and $30^{\circ}$ saccades.
Pursuit movements were studied by asking the patient to follow a periodically moving target at $18^{\circ} / \mathrm{se}$ cond. Optokinetic stimulation was produced using a projector (model 3400 , L.T. Instruments, Houston, Texas) and the induced nystagmus was recorded in both horizontal directions for three increasing velocity stimuli (25, 50 and 70 degrees per secod). The optokinetic stimulus was projected onto a screen in front of the patient and occupied approximately $35^{\circ}$ of the visual field. Caloric irrigation of 20 seconds duration was given using water at $30^{\circ} \mathrm{C}$ and then $44^{\circ} \mathrm{C}$ from a bath with automatic temperature control. The responses were recorded with the eyes closed. The slow phase nystagmus velocity was measured at the peak of the response. The ability to visually suppress the post-caloric nystagmus was tested about 100 seconds from the beginning of the irrigation by asking the patient to open his eyes and fixate a target. None of the patients were taking medication and all were asked not to use alcohol for 48 hours before the examination.

\section{RESULTS}

No neuro-ophthalmic abnormalities were detected in the clinical or electro-oculographic examinations of parents or siblings of the Friedreich's ataxia patients.

In the patients with Friedreich's ataxia the severity of the disease was variable. Some patients were bedridden and severely dysarthric by the age of 15 years and others were relatively normal at 35 years. No abnormalities in visual acuity, color vision, pupillary reactions, or visual fields were discovered in any patients who were able to co-operate fully in the tests. The fundi were normal in all cases. All the patients demonstrated abnormalities of ocular motility of varying degrees which correlated more with the severity of the general manifestations of the disease rather than with the age of the patient. The findings are given in Table I.

\section{Fixation and Pursuit System}

Fixation instability was clinically manifest in 3 patients as square wave jerks and electro-oculography showed the occurrence of square wave jerks in 6 of the 11 patients examined. The square wave jerks occurred at irregular intervals and often in small bursts. They were as frequent on the recordings with the eyes open as with the eyes closed. They occurred

TABLE

Ocular Motility Findings in Friedreich's Ataxia

\begin{tabular}{|c|c|c|c|c|c|c|c|c|}
\hline $\begin{array}{l}\text { Case; Sex } \\
\text { Age (yr) }\end{array}$ & $\begin{array}{c}\text { Square } \\
\text { Wave Jerks }\end{array}$ & $\begin{array}{l}\text { Pursuit } \\
\text { System }\end{array}$ & $\begin{array}{l}\text { Optokinetic } \\
\text { Nystagmus }\end{array}$ & $\begin{array}{l}\text { Gaze Paretic } \\
\text { Nystagmus }\end{array}$ & $\begin{array}{r}\text { Rebound } \\
\text { Nystagmus }\end{array}$ & F.F.S. & $\begin{array}{c}\text { Caloric } \\
\text { Responses }\end{array}$ & Saccades \\
\hline 1. M 15 & no & normal & $22,32,27$ & no & no & no & 10 & normal \\
\hline 2. $\mathrm{M} 17$ & no & normal & $16,21,25$ & no & no & no & 7 & normal \\
\hline 3. $F 18$ & no & + & $21,28,26$ & no & no & yes & 5 & normal \\
\hline 4. F 19 & no & + & $21,20,20$ & no & no & yes & 5 & normal \\
\hline 5. M 37 & no & ++ & $20,20,18$ & yes & yes & yes & 4 & dysmetria \\
\hline 6. M 21 & yes & + & $23,27,27$ & yes & no & yes & 4 & dysmetria \\
\hline 7. M 34 & yes & + & $20,26,24$ & no & no & yes & 10 & dysmetria \\
\hline 8. F 27 & yes & ++ & $10,12,12$ & yes & yes & yes & 4 & dysmetria \\
\hline 9. F 25 & yes & +++ & $4,3,2$ & yes & yes & yes & 5 & dysmetria \\
\hline 10. F 39 & no & +++ & $4,3,4$ & yes & yes & yes & 4 & dysmetria \\
\hline 11. F 15 & yes & +++ & $8,8,4$ & yes & yes & yes & 6 & dysmetria \\
\hline 12. M 20 & no & +++ & poor responses & yes & yes & yes & not tested & dysmetria \\
\hline 13. F 42 & yes & +++ & no responses & yes & yes & yes & not tested & dysmetria \\
\hline 14. M 36 & no & +++ & no responses & yes & yes & yes & not tested & dysmetria \\
\hline
\end{tabular}

The symbols,+++ , and +++ indicate the increasing degree of severity of defect in the pursuit system. The figures for Optokinetic Nystagmus represent the maximum nystagmus

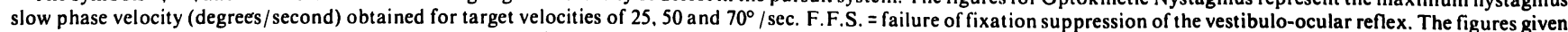
for Caloric Responses are the maximum slow phase velocities obtained for post-caloric nystagmus in degrees per second. 
rand omly to either side of the midline. The square wave jerks occurred for the most part in those patients whose pursuit system was relatively severely deranged (Table I).

Clinical testing of pursuit capabilities showed 2 patients who were considered to be normal (Cases 1,2). Two others (Cases 3,4) were normal when examined one year previously but were now found to have jerky pursuit. The remaining 10 patients all had jerky pursuit both horizontally and vertically. Electro-oculography confirmed the clinical impression. The patients with pursuit defects manifested marked inability to pursue targets moving at velocities of $18^{\circ} / \mathrm{sec}$ without the use of multiple small, "catch-up" saccades.

\section{Optokinetic Nystagmus}

Clinical optokinetic responses were tested in all patients using a hand-held rotating drum. Eight patients (Cases 1-8) were judged to have normal optokinetic responses which appeared to be symmetrical in both horizontal and vertical planes; 4 others showed diminished responses, and no responses were obtained in 2 cases (Cases 13,14).

The horizontal optokinetic responses were recorded by electrooculography at three different velocities. The responses obtained were variable and appeared to depend on the degree of the severity of the systemic manifestations of the disease. Three patients (Cases 9,10,11), who were severely affected, had very low initial slow phase velocities of between $4^{\circ} / \mathrm{sec}$ and $8^{\circ} / \mathrm{sec}$ for a target velocity of $25^{\circ} / \mathrm{sec}$, and when the stripe speed was increased to $50^{\circ} / \mathrm{sec}$ and $70^{\circ} / \mathrm{sec}$ they were completely unable to augment the slow phase velocity of their nystagmus. These 3 patients had marked defects of the pursuit system and were among the patients with clinically marked gaze paretic and rebound nystagmus. The remaining patients who were tested showed a marked variability in the range of optokinetic nystagmus slow phase velocities initially. None of them was able to increase significantly the slow phase velocity with increasing stimulus velocity. Some increased slightly their slow phase velocity for the stimulus at $50^{\circ} / \mathrm{sec}$ from that obtained at stimulus velocity of $25^{\circ} / \mathrm{sec}$ (Cases 1,2,3 and 7), others remained at their original velocity and still others reduced their velocity. When the target velocity was increased to $70^{\circ} / \mathrm{sec}$, no patient was able to increase the slow phase velocity of the optokinetic response. Some maintained the velocity obtained at $50^{\circ} / \mathrm{sec}$ and the majority lowered the response velocity. The one patient (Case 1) who showed the best optokinetic responses, for example, had slow phase velocities of $22 \pm 3^{\circ} / \mathrm{sec}, 32 \pm 2^{\circ} / \mathrm{sec}$ and $27 \pm$ $5^{\circ} / \mathrm{sec}$ for three stimulus velocities. All the other patients had significantly poorer responses than this for the $50^{\circ} / \mathrm{sec}$ and $70^{\circ} \mathrm{sec}$ velocities. The ranges obtained from our normal subjects were $25 \pm 4^{\circ} / \mathrm{sec}, 34 \pm 6^{\circ} / \mathrm{sec}$ and $40 \pm 9^{\circ} / \mathrm{sec}$.

\section{Gaze Paretic and Rebound Nystagmus}

Marked horizontal gaze paretic nystagmus was clinically observed in 6 patients. They also had upbeat nystagmus on upward gaze but no nystagmus on downward gaze. The nystagmus was most pronounced in the more severely disabled patients. In 3 other patients (Cases 5, 6 and 8), a few beats of poorly sustained gaze paretic nystagmus was seen when the eyes were held in eccentric gaze at $45^{\circ}$ from the midline. Some of the electrooculographic tracings confirmed the clinical observations and showed the slow phase of the nystagmus to have a decreasing exponential velocity characteristic of gaze paretic nystagmus (Zee et al, 1976).

Rebound nystagmus was sought clinically in all patients by having them first maintain eccentric gaze at $45^{\circ}$ from the midline for 20 seconds and then asking them to return the eyes to the midline. Prominent rebound nystagmus was seen in the 6 patients who showed marked gaze paretic nystagmus, but it could not be clinically detected in the other patients. One electro-oculographic tracing showed the slow phase of the rebound nystagmus to have a decreasing velocity exponential slope. A few jerks of rebound nystagmus were detected on the tracings of 2 of the other patients who had minimal gaze paretic nystagmus (Cases 5,8).
The rebound nystagmus lasted fro 3 to 15 seconds in different individui 3 .

\section{Vestibulo-ocular reflex}

The ability of the patient to suppress vestibular nystagmus by fixation was tested by having the patient fixate on an object rotating at the same velocity as his head. A pointer with a fixation object was held on the patient's head and the examiner moved the head from side to side and then up and down. When fixation suppression is normal no nystagmus is observed, but when it is inadequate the eyes are carried constantly off the target under the influence of the vestibulo-ocular reflex so that repeated saccades are needed to refixate the object and these appear as nystagmus (Zee, 1977). This test showed failure of fixation suppression of the vestibulo-ocular reflex in all 12 patients who had clinical impairment of the pursuit system. The test was positive in both horizontal and vertical planes.

Caloric testing was undertaken in conjunction with electro-oculography in 11 cases. The caloric responses were always bilaterally reduced and fairly symmetrical and were poor for both hot and cold irrigations and the maximum slow phase velocity obtained in our patients varied from $4^{\circ} / \mathrm{sec}$ to $10^{\circ} / \mathrm{sec}$. The degree of fixation suppression of the vestibular nystagmus resulting from the caloric stimulation could not be accurately assessed from most of the tracings because of the very poor, irregular, low amplitude responses obtained, but in 9 cases fixation did not appear to significantly alter the nystagmus responses. In the 2 patients (Cases 1,2) who had normal pursuit, there did seem to be total suppression of the nystagmus by fixation despite the low slow phase velocities obtained with the eyes closed. In our laboratory the normal range of slow phase velocities obtained for post-caloric nystagmus is $28 \pm 9^{\circ} / \mathrm{sec}$.

\section{Saccades}

Clinical testing of saccadic eye movements was performed for $30^{\circ}$ saccades to and away from the midline. Most saccades were judged to be accurate but a varying number were either hypometric or hypermetric. 
Hypometria appeared to be more frequent away from and hypermetria more frequent towards the midline.

A number of horizontal saccades of $10^{\circ}$ and $30^{\circ}$ were measured for each patient towards and away from the midline to right and left by electrooculography. All patients had saccadic velocities which fell within the normal range for saccades in our laboratory $\left(265 \pm 38^{\circ} / \mathrm{sec}\right.$ for $10^{\circ}$ saccades for both abducting and adducting saccades and $408 \pm 56^{\circ} / \mathrm{sec}$ for abducting and $436 \pm 66^{\circ} / \mathrm{sec}$ for adducting saccades). Four patients (Cases 1,2,3,4) made very precise normometric saccades and these were the 4 patients who were found to have good pursuit systems on their initial clinical examinations. The remaining 7 patients who were examined by electro-oculography all showed dysmetria, either hypermetria or hypometria, both towards or away from the midline, equally on rightward or leftward movements, between $13 \%$ and $28 \%$ of saccades measured for $10^{\circ}$ saccades and $30 \%$ and $44 \%$ for $30^{\circ}$ saccades. The hypometric saccades and hypermetric saccades were irregularly interspersed with normoliketric saccades. There was no significant difference in the number of hypometric or hypermetric saccades or in their direction towards or away from the midline in contrast to the clinical suspicion. The hypometric saccades were corrected by a single saccade to place the eyes on the target (dual step saccades) in over $95 \%$ of cases. The velocities of the second step of the saccades were within the range of normal. In the case of multiple step saccades it was not possible to determine accurately the velocities of the low amplitude third step from our recordings. All the hypermetric saccades were corrected by a single step.

\section{DISCUSSION}

The neuro-ophthalmic literature on Friedreich's ataxia is confused by the inexact diagnosis of most of the reported cases. Friedreich emphasized nystagmus as the only consistent ocular finding and, although nystagmus has been noted in several subsequent reports, many of the cases were far from typical (Whyte, 1898; Walsh and Hoyt, 1969; Tyrer, 1975). Periodic alternating nystagmus was said to be present in one case but the report of the clinical neurological features renders the diagnosis difficult to accept (Gorman and Brock, 1950). Horizontal gaze paresis (Kreindler et al, 1963) and pursuit difficulty and nystagmus (Spiller, 1910) in more typical cases have been described. An electro-oculographic study of 5 patients with Friedreih's ataxia (Baloh et al, 1975) showed the pursuit system to be universally deranged; 4 of the patients had gaze paretic nystagmus, 3 had hypoactive or reduced caloric responses and abnormal optokinetic responses and 3 had abnormal saccadic movements. A study of vestibular function in Friedreich's ataxia (Monday et al, 1978) showed most to have reduced caloric responses and several had abnormal pursuit and gaze paretic nystagmus.

Fixation instability, manifest as square wave jerks, was detected in 6 of our patients. Square wave jerks are conjugate saccadic movements of less than $3^{\circ}$ amplitude by which the eyes move off the fixation point and then, after a latent period of about $200 \mathrm{msec}$, return by a saccade to the fixation point. Such square wave jerks have a frequency of about $2 \mathrm{~Hz}$ (Dell'Osso et al, 1975). The occurrence of square wave jerks, with eyes open during fixation, is suggestive, but not diagnostic, of cerebellar disease (Zee et al, 1976; Troost and Daroff, 1977); they cannot be considered a specific sign of Friedreich's ataxia although they have been noted previously (Baloh et al, 1975; Dale et al, 1978; Monday et al, 1978).

Twelve of our 14 patients had pursuit defects manifest as "saccadic" or "cogwheel" pursuit, so-called because the movements resulting from the attempt to follow a slowly-moving target requires the addition of numerous small "catch-up" saccades in order to stay on the target. The patients were unable to make pursuit velocity match the target velocity of $18^{\circ} / \mathrm{sec}$. In our study we used sinusoidally-moving targets at a frequency of $0.72 \mathrm{~Hz}$ with an amplitude of $25^{\circ}$; normal subjects are able to perform excellent smooth pursuit with this type of predictable movement up to about $1 \mathrm{~Hz}$ (Young, 1971).

Smooth pursuit appears to be closely related, although not identical, to the slow phase velocity of optokinetic nystagmus. It is interesting, therefore, to compare the pursuit and optokinetic capabilities of our patients. The optokinetic system comprises two subsystems driven respectively by stimulation of central (foveal) and peripheral retina (Dichgans, 1977). The function of the peripheral optokinetic system is probably to complement the vestibulo-ocular reflex and to stabilize the eyes during movement of the external world (Robinson, 1977). During testing with a $35^{\circ}$ area of visual field both the fovea and a portion of the peripheral retina are stimulated by the stripe motion; consequently eye movements due to stimulation of both pursuit and peripheral optokinetic systems are present, the stripes being of such a large diameter that they could not be considered as a foveal optokinetic stimulus (Dichgans, 1977).

Our electro-oculographic recordings showed significant abnormalities in optokinetic nystagmus in all patients tested when more than one stimulus velocity was used, there being inability to augment normally the slow phase velocity of the response with increasing stimulus velocity. Five of the patients with abnormal pursuit (Cases 3-7) who were unable to match a pursuit target velocity of $18^{\circ} / \mathrm{sec}$ were able, under optokinetic stimulation, to immediately produce a slow phase velocity beyond this and also to slightly augment the slow phase velocity with increasing stimulus velocity, although less than in normal subjects. If the patients' slow phase velocity had remained at their pursuit level it would not have been possible, with steady state testing, to distinguish their optokinetic response from their smooth pursuit response. The face that they were able to augment, albeit slightly, their slow phase velocities beyond $18^{\circ} / \mathrm{sec}$ indicates that the peripheral optokinetic system contributed to the response (Robinson, 1977). Four other patients (Cases 811), who had very poor pursuit, gave 
very low abnormal optokinetic responses suggesting complete disruption of their optokinetic systems.

The slow phase velocity of optokinetic nystagmus can be increased by normal subjects as the velocity of the stimulus increases (Morisette et al, 1974) and may be fairly linear up to $80^{\circ} / \mathrm{sec}$ (Mizukoshi et $\mathrm{al}, 1977)$, the linearity depending largely on the area of the horizontal visual field being stimulated (Dichgans, 1977). With a suboptimal $\left(35^{\circ}\right)$ field of optokinetic stimulation as was used in our experiments, we found the normal patients gave responses decaying along the curve indicated by Dichgans (1977). The responses obtained from our patients were significantly below the normals except for the $25^{\circ} / \mathrm{sec}$ stimulus. An inability to augment the slow phase velocity of optokinetic nystagmus correlates experimentally (Takemori and Cohen, 1974) and clinically (Nemet and Ron, 1977) with lesions of the cerebellar flocculus and vermis. Abnormally low slow phase velocities of optokinetic nystagmus have been previously reported in Friedreich's ataxia, but only one stimulus velocity was tested (Baloh et al, 1975).

All of the patients who had deficient ocular pursuit were clinically unable to suppress by fixation their vestibuloocular reflex (Zee, 1977). Probably it is the pursuit system which overrides the vestibulo-ocular reflex during fixation of a target rotating at the same velocity as the head and, fixation may be considered as pursuit at zero velocity (Troost et al, 1976). Caloric testing in conjunction with electro-oculography in 9 patients showed apparent inability to suppress by fixation the caloric induced nystagmus. Only Cases 1 and 2 who had good pursuit systems had normal visual suppression. Such failure of fixation suppression of vestibular nystagmus clinically correlates with cerebellar and brain stem disease (Kato et al, 1977; Zee et al, 1976) and experimentally with floccular and nodular lesions (Hassul et al, 1976; Takemori and Cohen, 1974). All our patients had significantly reduced caloric responses and this has been noted previously in Friedreich's ataxia (Baloh et al, 1975; Monday et al, 1978). None of the patients had decreased hearing and the reason for the reduced caloric responses is not understood.

Gaze paretic nystagmus was seen in our patients when the eyes were held in horizontal eccentric gaze at $45^{\circ}$ from the midline. The eyes tended to drift off the target towards the primary position with a decreasing velocity exponential wave form so that repetitive saccades were required to return the eyes to the target resulting in a gaze paretic nystagmus. The neural network responsible for maintaining the eyes in an eccentric position is a neural integrator which integrates a pulse of unit activity and provides a constant innervation to the ocular motor neurones (Robinson, 1974). This integrator, located in the brain stem, appears to need a cerebellar input to maintain its function, so that either cerebellar or brain stem disease could result in its deficient action when gaze paretic or "integrator" nystagmus occurs.

We found rebound nystagmus clinically in 6 of our patients and in 2 others by electro-oculography. Interestingly, it was not seen in a previous electro-oculographic study of Friedreich's ataxia (Monday et al, 1978) but we have noted that it is usually difficult to detect unless the eyes are held in an eccentric position for at least 20 seconds before return to the midline. The duration and slow phase velocity of rebound nystagmus has been noted to increase with the duration and degree of eccentricity of attempted lateral gaze (Zee et al, 1976). The existence of rebound nystagmus in patients who show gaze paretic nystagmus may suggest the involvement of adaptive mechanisms (plasticity) attempting to repair the faulty brain stem integrator. It is possible that after maintained eccentric gaze, a compensating bias develops which assists in the maintenance of the eccentric ocular position. When the eyes return to the midline rebound nystagmus occurs due to the persistent bias and, as the bias decays, the rebound nystagmus disappears. Rebound nystagmus has been considered a sign of cerebellar disease (Hood et al, 1973).

Saccadic dysmetria, either hypermetria or hypometria and reduced saccadic velocity (Baloh et al, 1975; Monday et al, 1978), have been previously recorded in patients with Friedreich's ataxia. We did not observe reduction in saccadic velocities either for $10^{\circ}$ or $30^{\circ}$ saccades in our patients. Dysmetria was frequently observed, however, particularly for the larger amplitude saccades. Dual step hypometric saccades were common but did not occur predominantly either to right or left or towards or away from the midline and occurred in less than $50 \%$ of all saccades, so that this phenomenon could well be normal (Troost et al, 1974). Multiple step hypometric saccades occurred in less than $5 \%$ of our patients and since the initial step velocities were within the normal range this may also be a normal finding (Troost et al, 1974). Hypermetric saccades have received less study: they were frequent in our patients and could well be pathological since they are rare in normal subjects. The hypermetric saccades occurred equally towards or away from the midline. Experimental lesions of the vermis (Ritchie, 1976) and surgical lesions of the human vermis (Ron and Nemet, 1977) result in dysmetric saccades.

The oculomotor defects present in our patients with Friedreich's ataxia cannot be considered as specific manifestations of Friedreich's ataxia since they have all been noted previously in patients with cerebellar and brain stem disease (Troost and Daroff, 1977; Zee et al, 1976). In a spinocerebellar degenerative disease such as Friedreich's ataxia, the cerebellum and its connections with the brain stem ocular motor control complex are likely to be involved so that widespread abnormalities of eye movements are commonly seen and were present in all our patients. The cerebellar flocculus and vermis have been implicated in the generation of pursuit movements (Miles and Fuller, 1975) and optokinetic movements (Nemet and Ron, 1977). Disease involving their connections could explain the pursuit defect, gaze paretic nystagmus, rebound nystagmus, failure of fixation suppression of the vestibulo-ocular reflex, and inability to augment the slow phase velocity of 
optokinetic responses seen in our patients. The vermis is important in the control of saccadic movements (Optican and Robinson, 1978) and disease of its connections could be responsible for the saccadic hypermetria found in our patients with Friedreich's ataxia.

The prominence of individual ocular motility disorders in patients with Friedreich's ataxia obviously depends on the extent of the pathological process involved and they can be expected to appear at some stage of the disease. We have not undertaken a prolonged longitudinal study of our patients, but those who have been followed for more than a year do appear to have shown a deterioration in the ocular motor manifestations of their disease.

\section{ACKNOWLEDGEMENTS}

We thank Mabel Mai, M.Sc., Deborah Williams, B.Sc., Kathleen Douglas, B.A. and Lilly Blitzer, B.Sc. for technical assistance.

\section{REFERENCES}

ANDERMANN, E., REMILLARD, G., GOYER, C., BLITZER, L., ANDERMANN, F. and BARBEAU, A. (1976) Genetic and family studies in Friedreich's ataxia. Canad. J. Neurol. Sci., 3, 287-301.

ANDERMANN, F. (1976). Nicolaus Friedreich and degenerative atrophy of the posterior columns of the spinal cord. Canad. J. Neurol. Sci., 3, 275-277.

BALOH, R. W., KONRAD, H. R. and HONRUBIA, V. (1975). Vestibulo-ocular function in patients with cerebellar atrophy. Neurology (Minn.), 25, 160-168.

BARBEAU, A. (1978). Friedreich's ataxia 1978 - an overview. Canad. J. Neurol. Sci., 5, 161-165.

DALE, R. T., DIRBY, A. W. and JAMPEL, R. S. (1978). Square wave jerks in Friedreich's ataxia. Am. J. Ophthalmol., 85, 400-406.

DELL'OSSO, L. F., TROOST, B. T. and DAROFF, R. B. (1975). Macro square wave jerks. Neurology (Minn.), 25, 975-979.
DICHGANS, J. (1977). Optokinetic nystagmus as dependent on the retinal periphery via the vestibular nucleus. In: Control of gaze by brain stem neurons. Developments in Neuroscience. Vol. I, (BAKER, R. and BERTHOZ, A., eds.) pp. 261-266.

GEOFFROY, G., BARBEAU, A., BRETON, G., LEMIEUX, B., LEGER, C., AUBE, M., BOUCHARD, J. P. (1976). Clinical description and roentgenologic evaluation of patients with Friedreich's ataxia. Canad. J. Neurol. Sci., 3, 279-286.

GORMAN, W. F. and BROCK, S. (1950). Periodic alternating nystagmus in Friedreich's ataxia. Am. J. Ophthalmol., 33, 860864.

HASSUL, M., DANIELS, P.D. and KIMM, J. (1976). Effects of bilateral flocculectomy on the vestibulo-ocular reflex in the chinchilla. Brain Research, 118, 339-343.

HOOD, J. D., KAYAN, A. and LEECH, J. (1973). Rebound nystagmus. Brain, 96, 507526.

KATO, I., KIMURA, Y., AOYAGI, M., MIZUKOSHI, K. and KAWASAKI, T. (1977). Visual suppression of caloric nystagmus in normal individuals. Acta Otolaryngol., 83, 245-251.

KREINDLER, A., POILICI, I. and CRIGHEL, E. (1963). Das Symptom des "erschwerten Seitenblicks" bei heredodgenerativen spinocerebellaren Erkrankungen. Nervenarzt, 34, 504-506.

MILES, F. A. and FULLER, J. H. (1975). Visual tracking and the primate flocculus. Science, 189, 1000-1002.

MIZUKOSHI, K., FABIAN, P. and STAHLE, J. (1977). Optokinetic test comprising both acceleration and constant velocity stimulation (ACV-OKN test). Acta Otolaryngol., 84, 155-165.

MONDAY, L. A., LEMIEUX, B., ST. VINCENT, H. and BARBEAU, A. (1978). Clinical and electronystagmographic findings in Friedreich's ataxia. Canad. J. Neurol. Sci., 5, 71-73.

MORISSETTE, Y., ABEL, S. M. and BARBER, H. O. (1974). Optokinetic nystagmus in otoneurological diagnosis. Canad. J. Otolaryngol., 3, 348-362.

NEMET, P. and RON, S. (1977). Cerebellar rôle in smooth pursuit movement. Docum. Ophthalmol., 43, 101-107.

OPTICAN, L. and ROBINSON, D. A. (1978). Cerebellar dependent adaptation of the saccadic system. Abstracts. Second Congress of the International Society of NeuroOphthalmology, Washington, Maryland.
RITCHIE, L. (1976). Effects of cerebellar lesions on saccadic eye movements. J. Neurophysiol., 39, 1246-1256.

ROBINSON, D. A. (1974). The effects of cerebellectomy on the cat's vestibulo-ocular integrator. Brain Research, 71, 195-207.

ROBINSON, D. A. (1977). Vestibular and optokinetic symbiosis: and example of explaining by modelling. In: Control of gaze by brain stem neurons. Developments in Neuroscience. Elsevier/North Holland Biomedical Press, Vol. I. (BAKER, R. and BERTHOZ, A., eds.) pp 49-58.

RON, S. and NEMET, P. (1977). The cerebellum involvement in the generation of saccades. Docum. Ophthalmol., 43, 109-114.

SPILLER, W. G. (1910). Friedreich's ataxia. J. Nerv. Ment. Dis., 37, 411-435.

TAKEMORI, S. and COHEN, B. (1974). Loss of visual suppression of vestibular nystagmus after flocculus lesions. Brain Research, 72, 213-224.

TROOST, B. T. and DAROFF, R. B. (1977). The ocular motor defects in progressive supranuclear palsy. Ann. Neurol., 2, 397403.

TROOST, B. T., DELL'OSSO, L. F. and DAROFF, R. B. (1976). Effects of visual pursuit deficit on the human vestibuloocular reflex. Neurology (Minn.), 26, 352353.

TROOST, B. T., WEBER, R. B. and DAROFF, R. B. (1974). Hypometric saccades. Am. J. Ophthalmol., 78, 1002-1005.

TYRER, J. H. (1975). Friedreich's ataxia. In: Handbook of Clinical Neurology. North Holland Press., Vol. 21. (VINKEN, P. J. and BRUYN, E. W., eds.) pp 319-364.

WALSH, F. B. and HOYT, W. F. (1969). Clinical Neuro-Ophthalmology. Third Edition. The Wiliams and Wilkis Co., Vol. I. pp 919922.

WHYTE, J. M. (1898). Four cases of Friedreich's ataxia with a critical digest of recent literature on the subject. Brain, 21, 72-136.

YOUNG, L. R. (1971). Pursuit eye tracking movements. In: The control of eye movements. Academic Press. (BACH-YRITA, P., COLLINS, C. C. and HYDE, J. E., eds.) pp 429-443,

ZEE, D. S. (1977). Suppression of vestibular nystagmus. Ann. Neurol., I, 207.

ZEE, D. S., YEE, R. D., COGAN, D. G., ROBINSON, D. A. and ENGEL, W. K. (1976). Ocular motor abnormalities in hereditary cerebellar ataxia. Brain, 99, 207234. 